\title{
Research on the Institutionalized Management of Applying the Mechanical Equipments Safely in Construction Project
}

\author{
Wenxia Zhu \\ Xi'an International University, Xi'an Shaanxi, 710077
}

\begin{abstract}
Keywords: Construction Project; Mechanical Equipments; Institutionalized management; Safe Construction
\end{abstract}

\begin{abstract}
As the rapid development of the construction industry and the architectural techniques, China has made great progress on mechanical equipment installation engineering; at the some times, people also begins paying attention to not only the safety of the mechanical equipments and the quality of the construction projects, but also the safety management of the worksites. In order to create a safe circumstance for the mechanical equipments, it is necessary to establish the relevant safety institutions for managing the construction project. What's more, in order to ensure the quality of the project, the smooth development of the project, and the safety of the project, it is necessary to manage and control the project overall and build a sound institution system for keeping the project developing smoothly. It is also necessary to standardize the relevant issues by the strict institution, such as on the installing the electromechanical equipments, on choosing the equipments, on organizing the staff who construct the project, and on standardizing the operators' operative specifications. Especially, to an enterprise, the institutionalized management determines not only the managerial results and the managerial quality, but also the further development of the enterprise. As the crucial segment of maintaining the smooth operation of the enterprise's whole managerial system, institutionalized management is the important standard to examination if the managerial system of an enterprise is scientific. How to do well in the safety management of the mechanical equipment during the construction process, and how to improve the safety management so that the managerial activities would be more scientific and more efficient have become the very issue that the managers should deliberate much more.
\end{abstract}

Nowadays, as the development of the mechanical equipment engineering, its managerial system has been highlighted, under this background, how to make a overall planning of a project so that the benefits of the project will be better, the quality of it will be higher, and the some time, it would not damage the environment have become a very issue that we have to think about a lot ${ }^{[1]}$. The institutionalized management of keeping the safety of the mechanical equipments always is not only the key point of the managerial activities, but the main measures for improving the working efficiency of the enterprises, for improving their overall ability, and for keeping the safety at the worksite. The institutionalized management means make a overall arrangement about a lot factors such as the functions of the project, the infrastructures, the project quality, the project schedule, the management and the operation, the human resource management, and the field management, etc, so as to ensure the smooth operation of the enterprise on constructing the project. At present, the main works of the constructors are to control the quality and the circumstance of the construction project, to make an overall arrangement about the project, and to implement the dynamic and systematic institutionalized management, so as to improve the quality of the project; at the some time, it also could create a safer construction circumstance.

\section{The present safety problems of the institutionalized management on the mechanical equipments of the construction project}

At present, constructors often pay more attention to the process of the constructing but neglect the management of the system, this phenomenon causes the mechanical equipments could not be maintained and stored very well during the construction process. First, some construction 
companies do not establish a sound managerial system. In China, there are so many construction companies, which scales are different, that the small companies could not establish the special department for managing the mechanical equipments, at the some time, these equipments could not be maintained and storied very well; the operators often operate these equipments wrong. Second, the safety management system of the mechanical equipments is unsound [2]. Although the construction enterprises have established the managerial system of the mechanical equipments and have applied the system, but because the contents of the system are unsound and they are not overall, so the implementation of the system lacks enough supervision, so that the system of these enterprises is superficial, it has little practical significance.

At present, when the mechanical equipments will be used, many operation companies often focus on the construction at the worksite, or focus on the purchasing segment, they often think little of the design of installation, so that the design is apart from the system, and the project may be in danger later. The professional knowledge of the designers is the key factor that determines the final benefits of the projects. But, at present, the professional abilities of many designers are low, so that their designs are not sound. When these designs are applied, many problems will be occurred. This would not only delay the normal construction schedule, but also badly influence the normal construction circumstance of the worksite. If these problems bring any quality problems or safety problem, the project would be reworked partly, even would be reworked totally. What's more, this would increase the cost of the project, bring some safety problems, and decline the project quality in the end [3].

The quality of the equipment determines if the project could be constructed smoothly, it is not only the key factor ensures the project could be operated with a high quality, but also the key factor of the safety system. When the enterprises choose the equipments, if the equipments are not accord with the relevant standards of the guilds or the country, or there are any defective in the equipments, the construction project would be influenced badly. Especially some inferior group wares and spares, these tiny parts, which are the potential risks, often bring the safety misadventures [4]. Some installation companies only chase the economic benefits, but neglect the qualities of the equipments, or they haven't check in the equipments that they had purchased, and some suppliers provide the wrong data that are the crucial information for the normal operation of the equipments, so that the equipments could not work smoothly, or the equipments would be damaged. If theses problems happen, the project would be at risks. Second, although some companies have pay attention to the purchase and examination about the equipments, but they haven't made a point of maintaining and replacing the old equipments, and haven't made a point of computing the depreciation; at the some time, there is no the unified standard procedure for treating the equipments, so that the equipments are overwork, and they could not be replaced timely. These problems above would bring a lot of safety risks and the relevant quality problems; and they would badly influence the stability of the project.

To the constructor company, they often focus on the process of construction but make a serious overall arrangement on the whole project. The safety system is the key point of the management forever, and the managerial result of this part is directly related to the following development of the project, it is very crucial to the safety of the project. However, most of the enterprises have been aware of the importance of the institutionalized management, but they still haven't know the importance very well, their institutionalized management is still in the exploratory stage, so that the managers and operators have not a clear understanding about it, and they are lack of the correct senses about it as well, so the institutionalized management is implemented superficially. This brings a lot of problems and risks to the application oh the mechanical equipment. First, the institutionalized management should be overall planning and systematic planning, but the managers still pay attention to the construction control and quality control, neglect the other parts such as the safety management, this is not correct, and this would bring a lot of problems and risks to the following works. This kind of managerial way is defective, and it blocks the further development of enterprise [5]. 


\section{The countermeasures for strengthening the institutionalized management on applying the mechanical equipments safely in the construction project}

Only the managers have a sound understanding about the institutionalized management could they feel urgent and make their mind on making the stricter rules, and then, to follow these rules; at the some time, to supervise the implementation of these rules, so as to build a sound construction circumstance. Therefore, in order to promote the further development of the institutionalized management, it is necessary to let the managers and the decision makers understand the importance of it, and let them highlight it by knowing the importance of the institutionalized management very well, and then, they could establish the targeted policies and plan the more scientific managerial strategies. By this way, the institutionalized management could be more reasonable, could be more targeted; at the some time, the managerial works would be more modern, more open, and the every department of the enterprise would be more effective, only by this way could the enterprise goes smoothly and have a effective further development.

If a good policy is lack of supervision, it would be difficult in practice. Therefore, in order to ensure the efficiency of the institutionalized management, it is necessary to improve the supervision system, and built the overall executive system, so that the policy could be implemented well from the very beginning until the implementation stage; at the some time, to supervise the implementation so as to ensure the policy is implemented effectively, and so as to promote the further development of the enterprise. The most important thing is to improve the supervision system. Institutionalized management has its instinctive particularity, it aims for the individual behaviors, it directly influences the behaviors of the workers, and therefore, in order to avoid the mistakes of the workers, and in order to avoid safety misadventures, it is necessary to improve the supervision system, so as to promote the managerial works to be carried out orderly [6].

The procedure of institutionalized management is complex, and the institutionalized management involves a wide range of factors, a lot of units and participators take part in it, so, to implement a sound managerial activity, the managers should arrange all the segments and factors systematically, and manage the project overall. Only a manger with high quality could the manager make progress in the complex construction circumstance, and make the targeted managerial rules, so as to ensure the managerial works could be implemented well. Therefore, in order to ensure the smooth implementation of the institutionalized management, it is necessary to improve the senior executives' professional abilities. In order to ensure the quality of the managers and the efficiency of the managerial activities, it is necessary to recruit the managers seriously in the recruitment process, and recruit the very person who is fit for the needs of the enterprise. What's more, the enterprises should train their managers any time if it is necessary, it could not only let the managers establish the correct career opinion, but also improve the professional abilities of the managers. Only by improving the professional abilities of the managers could the managerial works be implemented smoothly, at the some time, the quality of the institutionalized management could be improved, the construction activities would be safer and safer.

\section{Conclusion}

The safety management of the mechanical equipment in the construction project is very important, it not only influences the schedule of the construction, but also influences the safety of the constructor; it is the key factor that determines if the builders could acquire to the sound benefits. There are so many kinds of mechanical equipments that are used in the construction projects that it is difficult to manage these equipments, in order to ensure the safety and the smooth operation of these equipments, the constructors must strengthen the safety management of the equipments, improve their safety management of these equipments, and provide more safety guidance to the operator, so as to take the best of these mechanical equipments, and ensure the schedule of the project. 


\section{References}

[1] Zhang Zhitao. Brief Analysis on the Problems and the Countermeasures on the Safety Management of the Mechanical Equipments of the Construction Project[J]. Jiangxi Building Materials, 2017, (19):285+291.

[2] Shan Peng. Brief Analysis on the Potential Safety Risks and its Countermeasures in the Construction of the High Buildings[J]. Construction Materials \& Decoration, 2017, (02):11-12.

[3] Shao Lin. Research on the Optimization of the Total Quality Control of the ABC International Piazza Project[D]. East China University, 2017.

[4] Liu Zhujing. Brief Discussion on the Institutionalized Management on the Using the Mechanical Equipments Safely during a Construction Project[J]. Technology Innovation and Application, 2016, (11):254.

[5] Zeng Wei. Research on the Safety Risk Management of the Crane during Constructing a House[D]. Guangxi University, 2015.

[6] Zhang Zhenfu. Discussion on the Institutionalized Management on Using the Mechanical Equipments Safely during a Construction Project[J]. Modern Property Management, 2013, (09):53-54.

[7] He Chunyu. The Safety Management of the Mechanical Equipment in the Construction Project[J]. China New Technologies and Products, 2011, (11):89. 